\title{
Distal Bile Duct Cancer by AJCC v7 Stage
}

National Cancer Institute

\section{Source}

National Cancer Institute. Distal Bile Duct Cancer by A/CC v7 Stage. NCI Thesaurus. Code C134810.

A term that refers to the staging of distal bile duct cancer according to the American Joint Committee on Cancer, 7 th edition. 